\title{
OPTIMALISASI PELAKSANAAN PROYEK DENGAN METODE CPM (CRITICAL PATH METHODE)
}

\author{
${ }^{1}$ Annisaa Dwiretnani, ${ }^{2}$ Arrazaq Kurnia \\ ${ }^{1}$ Dosen Fakultas Teknik Universitas Batanghari \\ ${ }^{2}$ Mahasiswa Teknik Sipil Universitas Batanghari \\ annisaa.dwiretnani@gmail.com
}

\begin{abstract}
ABSTRAK
Bangunan Mapolsek Danau Teluk yang lama sudah tidak memadai baik dari segi kualitas maupun dari kuantitas untuk menampung seluruh kegiatan pengguna didalamnya dengan baik dan lancer. pembangunan satu unit kantor Mapolsek Danau Teluk, yang berlokasi di Jl. KH. M. Saleh., dimaksudkan untuk menggantikan fungsi bangunan lama. Mapolsek Danau Teluk ini bertingkat dua dengan luas lantai 232,5 $\mathrm{m}^{2}$. Data yang digunakan pada penelitian ini yaitu data primer dan sekunder.Dalam melakukan analisa, perhitungan yang dilakukan peneliti berdasarkan pada data dari Proyek Pembangunan Mapolsek Danau Teluk. Adapun tujuan mengetahui jaringan kerja, dan lintasan kritis serta Menghitung waktu yang optimal untuk menyelesaikan proyek pembangunan Mapolsek Danau Teluk Kota Jambi dengan menggunakan metode CPM (Critical Path Methode). Dari hasil analisis diketahui jalur lintasan kritis terdapat pada 19 pekerjaan dengan durasi pemyelesaian proyeknya 203 hari
\end{abstract}

Kata Kunci: Optimalisasi, Proyek konstruksi, CPM

\section{PENDAHULUAN}

Proyek konstruksi berkembang sejalan dengan perkembangan kehidupan manusia dan kemajuan teknologi. Bidang-bidang kehidupan manusia yang makin beragam menuntut industri jasa konstruksi, membangun proyek-proyek konstruksi sesuai dengan keragaman bidang tersebut.

Pada pembangunan gedung misalnya, diperlukan adanya penanganan manajemen penjadwalan kerja yang baik, karena itu perlu ditangani dengan perhitungan yang cermat dan teliti. Suatu proyek dikatakan baik jika penyelesaian proyek tersebut efisien, ditinjau dari segi waktu dan biaya serta mencapai efisien kerja, baik manusia maupun alat (Badri, 1997).

Bangunan Mapolsek Danau Teluk yang lama sudah tidak memadai baik dari segi kualitas maupun dari kuantitas untuk menampung seluruh kegiatan pengguna didalamnya dengan baik dan lancar. Dari segi kualitas, bangunan mapolsek lama telah berumur cukup tua dan kondisi bangunannya sudah memprihatinkan. Sedangkan dari segi kuantitas, bertambahnya civitas yang ada didalamnya, dan diperlukannya penambahan ruangan yang lebih kompleks, menuntut adanya bangunan baru yang lebih dapat menunjang segala kebutuhan dan aktivitas didalamnya.

Pembangunan satu unit kantor mapolsek danau teluk, yang berlokasi di Jl. KH.M.Saleh., dimaksudkan untuk menggantikan fungsi bangunan lama. Mapolsek Danau Teluk ini bertingkat dua dengan luas lantai $232,5 \mathrm{~m}^{2}$.

Proyek merupakan sekumpulan aktivitas yang saling berhubungan. Ada titik awal dan titik akhir serta hasil tertentu. Proyek biasanya bersifat lintas fungsi organisasi sehingga membutuhkan bermacam keahlian (skills) dari berbagai profesi dan organisasi. Setiap proyek adalah unik, bahkan tidak ada dua proyek yang persis sama. Proyek adalah aktivitas sementara dari personil, material, serta sarana untuk menjadikan/ mewujudkan sasaran proyek dalam kurun waktu tertentu yang kemudian berakhir (PT. Pembangunan Perumahan, 2003).

Proyek yaitu sebuah usaha yang dilakukan dengan cara bertanggung jawab untuk menghasilkan sebuah produk, jasa, yang menghasilkan suatu hasil tertentu (Lewis, 2005).

Manajemen proyek adalah yaitu suatu metode pengelolaan yang dikembangkan secara ilmiah dan intensif sejak pertengahan abad ke-20 untukmenghadapi kegiatan khusus yang berbentuk proyek. Hal ini merupakan usaha agar tujuan kegiatan dapat tercapai secara efisien dan efektif.

Efektif dalam hal ini adalah di mana hasil penggunaan sumber daya dan kegiatan sesuai dengan sasarannya yang meliputi kualitas, biaya, waktu, dan lain-lainnya. Sedangkan efisien diartikan penggunaan sumber daya dan pemilihan sub-kegiatan secara tepat yang meliputi jumlah, jenis, saat penggunaan sumber lain dan lain-lain. 
Pengendalian waktu merupakan suatu rencana monitoring harus merangkum masalah-masalah yang secara aktif selalu diamati, dicatat dan dilaporkan selama berlangsungnya pelaksanaan proyek konstruksi.

Pada umumnya ada 3 jenis metode yang digunakan dalam pengendalian waktu pada pelaksanaan proyek konstruksi yaitu :

1. Metode CPM (Critical Path Methode)

2. PDM (Precedence Diagram Method)

3. PERT (Programe Evaluation and Review Technique)

Menurut Levin dan Kirkpatrick (1972), metode Jalur Kritis (Critical Path Method - CPM), yakni metode untuk merencanakan dan mengawasi proyek-proyek merupakan sistem yang paling banyak dipergunakan diantara semua sistem lain yang memakai prinsip pembentukan jaringan. Dengan CPM, jumlah waktu yang dibutuhkan untuk menyelesaikan berbagai tahap suatu proyek dianggap diketahui dengan pasti, demikian pula hubungan antara sumber yang digunakan dan waktu yang diperlukan untuk menyelesaikan proyek. CPM adalah model manajemen proyek yang mengutamakan biaya sebagai objek yang dianalisis (Siswanto, 2007). CPM merupakan analisa jaringan kerja yang berusaha mengoptimalkan biaya total proyek melalui pengurangan atau percepatan waktu penyelesaian total proyek yang bersangkutan.

Jaringan Kerja (Network planning) pada prinsipnya adalah hubungan ketergantungan antara bagianbagian pekerjaan yang digambarkan atau divisualisasikan dalam diagram network. Dengan demikian dapat dikemukakan bagian-bagian pekerjaan yang harus didahulukan, sehingga dapat dijadikan dasar untuk melakukan pekerjaan selanjutnya dan dapat dilihat pula bahwa suatu pekerjaan belum dapat dimulai apabila kegiatan sebelumnya belum selesai dikerjakan.

Dalam metode CPM (Critical Path Method - Metode Jalur Kritis) dikenal dengan adanya jalur kritis, yaitu jalur yang memiliki rangkaian komponen-komponen kegiatan dengan total jumlah waktu terlama.

Jalur kritis terdiri dari rangkaian kegiatan kritis, dimulai dari kegiatan pertama sampai pada kegiatan terakhir proyek (Soeharto, 1999). Lintasan kritis (Critical Path) melalui aktivitas-aktivitas yang jumlah waktu pelaksanaannya paling lama. Jadi, lintasan kritis adalah lintasan yang paling menentukan waktu

Menurut Badri (1997), manfaat yang didapat jika mengetahui lintasan kritis adalah sebagai berikut :

1. Penundaan pekerjaan pada lintasan kritis menyebabkan seluruh pekerjaan proyek tertunda penyelesaiannya.

2. Proyek dapat dipercepat penyelesaiannya, bila pekerjaan-pekerjaan yang ada pada lintasan kritis dapat dipercepat.

3. Pengawasan atau kontrol dapat dikontrol melalui penyelesaian jalur kritis yang tepat dalam penyelesaiannya dan kemungkinan di trade off (pertukaran waktu dengan biaya yang efisien) dan crash program (diselesaikan dengan waktu yang optimum dipercepat dengan biaya yang bertambah pula) atau dipersingkat waktunya dengan tambahan biaya lembur.

4. Time slack atau kelonggaran waktu terdapat pada pekerjaan yang tidak melalui lintasan kritis. Ini memungkinkan bagi manajer/pimpro untuk memindahkan tenaga kerja, alat, dan biaya ke pekerjaanpekerjaan di lintasan kritis agar efektif dan efisien. 


\section{METODE PENELITIAN}

Secara ringkas, penelitian ini bisa digambarkan dengan diagram alir berikut ini

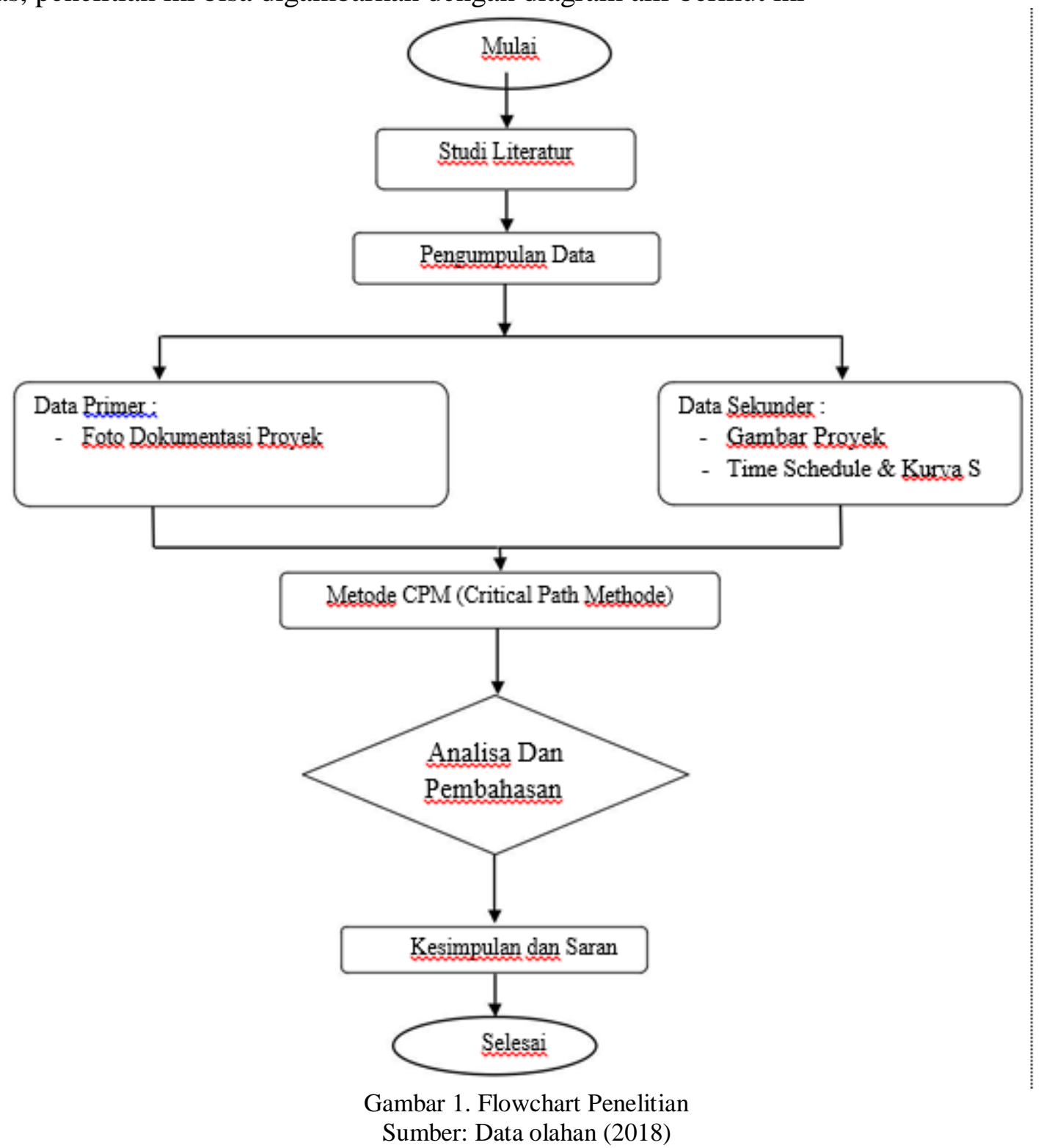

\section{HASIL DAN PEMBAHASAN}

\section{Menginventarisasi Pekerjaan (Kegiatan Proyek)}

Langkah pertama yang dilakukan dalam menyusun jaringan kerja (network planning) adalah menginventariskan kegiatan. yaitu dengan cara pengkajian dan pengindefikasian lingkup proyek, menguraikan atau memecahkannya menjadi kegiatan-kegiatan pada proyek. Kegiatan-kegiatan pembangunan Mapolsek Danau Teluk Kota Jambi dapat terlihat pada tabel 1 dibawah ini :

\section{Tabel 1. Urutan Pekerjaan (Kegiatan Proyek)}

\begin{tabular}{clc}
\hline No & \multicolumn{1}{c}{ Jenis Kegiatan } & Kode \\
\hline A & Pekerjaan Pendahuluan & \\
1 & Pekerjaan persiapan & AA \\
B & Pekerjaan lantai I & BA \\
2 & Pekerjaaan tanah dan urugan & BB \\
3 & Pekerjaan pondasi & BC \\
4 & Pekerjaan struktur beton & BD \\
5 & Pekerjaan tangga & BE \\
6 & Pekerjaan pasangan dan plasteran & BF \\
7 & Pekerjaan kusen dan jendela &
\end{tabular}


8 Pekerjaan Lantai $\quad$ BG

$9 \quad$ Pekerjaan plafond dan rangka $\quad \mathrm{BH}$

10 Pekerjaan sanitasi $\quad$ BI

11 Pengecetan dan finishing $\quad$ BJ

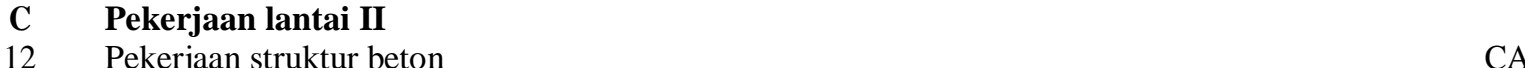

13 Pekerjaan pasangan dan plaster $\quad$ CB

14 Pekerjaan kusen, daun pintu, jendela dan $\quad$ CC

15 Pekerjaan keramik lantai dan dinding KW/WC $\quad$ CD

16 Pekerjaan plafond dan rangka $\quad$ CE

17 Pekerjaan sanitasi $\quad$ CF

18 Pekerjaan atap $\quad$ CG

19 Pekerjaan pengecatan dan finishing $\quad \mathrm{CH}$

20 Pekerjaan Elektrikal $\quad$ DA

21 Pekerjaan Plumbing $\quad$ EA

Sumber : CV. Archigrav Design Consultant

\section{Menentukan Perkiraan Waktu (Durasi) Pekerjaan Proyek}

Langkah ini adalah menentukan perkiraan kurun waktu bagi setiap kegiatan yang ada pada Pembangunan Mapolsek Danau Teluk yang berlokasi di Jl. KH.M.Saleh terlihat pada tabel 2 dibawah ini:

\section{Tabel 2. Durasi Pekerjaan (Kegiatan Proyek)}

\begin{tabular}{clcc}
\hline \multicolumn{1}{c}{ Jenis Kegiatan } & Kode & Durasi (hari) \\
\hline No & \multicolumn{1}{c}{ Pekerjaan Pendahuluan } & \\
1 & Pekerjaan persiapan & AA & 21 \\
B & Pekerjaan lantai I & BA & 14 \\
2 & Pekerjaaan tanah dan urugan & BB & 14 \\
3 & Pekerjaan pondasi & BC & 21 \\
4 & Pekerjaan struktur beton & BD & 7 \\
5 & Pekerjaan tangga & BE & 14 \\
6 & Pekerjaan pasangan dan plasteran & BF & 7 \\
7 & Pekerjaan kusen dan jendela & BG & 14 \\
8 & Pekerjaan Lantai & BH & 7 \\
9 & Pekerjaan plafond dan rangka & BI & 7 \\
10 & Pekerjaan sanitasi & BJ & 7 \\
11 & Pengecetan dan finishing & & \\
C & Pekerjaan lantai II & CA & 14 \\
12 & Pekerjaan struktur beton & CB & 14 \\
13 & Pekerjaan pasangan dan plaster & CC & 14 \\
14 & Pekerjaan kusen, daun pintu, jendela dan ventilasi & CD & 14 \\
15 & Pekerjaan keramik lantai dan dinding KW/WC & CE & 7 \\
16 & Pekerjaan plafond dan rangka & CF & 7 \\
17 & Pekerjaan sanitasi & CG & 7 \\
18 & Pekerjaan atap & CH & 7 \\
19 & Pekerjaan Pengecatan dan finishing & DA & 7 \\
20 & Pekerjaan Elektrikal & EA & \\
21 & Pekerjaan Plumbing & & \\
\hline
\end{tabular}

Sumber : CV. Archigrav Design Consultant

\section{Menyusun Setiap Kegiatan}

Urutan kegiatan-kegiatan yang sesuai dengan logika ketergantungan pada pembangunan Mapolsek Danau Teluk Kota Jambi, seperti pada tabel dibawah ini : 
Tabel 3. Daftar Kegiatan-Kegiatan Pengikut Dan Pendahulu

\begin{tabular}{clccc}
\hline No & \multicolumn{1}{c}{ Jenis Kegiatan } & Kode & $\begin{array}{c}\text { Predecessor } \\
\text { (Pendahulu) }\end{array}$ & $\begin{array}{c}\text { Sucessor } \\
\text { (Pengikut) }\end{array}$ \\
\hline A & Pekerjaan Pendahuluan & AA & - & \\
1 & Pekerjaan persiapan & & & BA \\
B & Pekerjaan lantai I & BA & AA & BB \\
2 & Pekerjaaan tanah dan urugan & BB & BA & BC \\
3 & Pekerjaan pondasi & BC & BB & BD, BE \\
4 & Pekerjaan struktur beton & BD & BC & BF \\
5 & Pekerjaan tangga & BE & BC & BG \\
6 & Pekerjaan pasangan dan plesteran & BF & BD, BE & BH \\
7 & Pekerjaan kusen dan jendela & BG & BF & BH \\
8 & Pekerjaan lantai & BG & BI \\
9 & Pekerjaan plafond dan rangka & BH & BJ \\
10 & Pekerjaan sanitasi & BI & BI & CA \\
11 & Pengecetan dan finishing & BJ & & \\
C & Pekerjaan lantai II & & BJ & CB \\
12 & Pekerjaan struktur beton & CA & CA & CC \\
13 & Pekerjaan pasangan dan plaster & CB & CB & CD \\
14 & Pekerjaan kusen, daun pintu, jendela dan ventilasi & CC & CC & CE \\
15 & Pekerjaan keramik laintai dan dinding KW/WC & CD & CD & CF \\
16 & Pekerjaan plafond dan rangka & CE & CE & CG, CH \\
17 & Pekerjaan sanitasi & CF & CF & EA \\
18 & Pekerjaan atap & CG & CF & DA \\
19 & Pekerjaan pengecatan dan finishing & CH & CH & - \\
20 & Pekerjaan Elektrikal & DA & CH & - \\
21 & Pekerjaan Plumbing & EA & & \\
\hline
\end{tabular}

Sumber : CV. Archigrav Design Consultant

Mengindentifikasi Jalur Kritis, Total Float, Waktu Penyelsaian Proyek

Float adalah tenggang waktu suatu kegiatan tertentu yang non kritis dari Proyek Pembangunan Mapolsek Danau Teluk Kota Jambi.

Tabel 4. Tabel Total Float

\begin{tabular}{|c|c|c|c|c|c|c|c|c|}
\hline \multirow[b]{3}{*}{ No } & \multirow{3}{*}{$\begin{array}{c}\text { Kode } \\
\text { Kegiatan } \\
\end{array}$} & \multirow{3}{*}{$\begin{array}{c}\text { Waktu } \\
\text { Hari }\end{array}$} & \multirow{2}{*}{\multicolumn{2}{|c|}{ Perhitungan }} & \multicolumn{2}{|c|}{ Perhitungan } & \multirow[b]{2}{*}{ Total } & \multirow[b]{3}{*}{ Keterangan } \\
\hline & & & & & & & & \\
\hline & & & ES & EF & LS & $\mathbf{L F}$ & Float & \\
\hline 1 & AA & 21 & 0 & 21 & 7 & 0 & 0 & Kritis \\
\hline 2 & BA & 14 & 21 & 35 & 28 & 28 & 0 & Kritis \\
\hline 3 & BB & 14 & 35 & 49 & 42 & 42 & 0 & Kritis \\
\hline 4 & $\mathrm{BC}$ & 21 & 49 & 70 & 56 & 56 & 0 & Kritis \\
\hline 5 & BD & 7 & 70 & 77 & 77 & 77 & 0 & Kritis \\
\hline 6 & $\mathrm{BE}$ & 14 & 70 & 84 & 77 & 84 & 7 & - \\
\hline 7 & $\mathrm{BF}$ & 7 & 84 & 91 & 84 & 98 & 14 & - \\
\hline 8 & BG & 14 & 84 & 98 & 91 & 91 & 0 & Kritis \\
\hline 9 & BH & 7 & 98 & 105 & 105 & 105 & 0 & Kritis \\
\hline 10 & BI & 7 & 105 & 112 & 112 & 112 & 0 & Kritis \\
\hline 11 & BJ & 7 & 112 & 119 & 119 & 119 & 0 & Kritis \\
\hline 12 & CA & 14 & 119 & 133 & 126 & 126 & 0 & Kritis \\
\hline 13 & $\mathrm{CB}$ & 14 & 133 & 147 & 140 & 140 & 0 & Kritis \\
\hline 14 & $\mathrm{CC}$ & 14 & 147 & 161 & 154 & 154 & 0 & Kritis \\
\hline 15 & $\mathrm{CD}$ & 14 & 161 & 175 & 168 & 168 & 0 & Kritis \\
\hline 16 & $\mathrm{CE}$ & 7 & 175 & 182 & 182 & 182 & 0 & Kritis \\
\hline 17 & $\mathrm{CF}$ & 7 & 182 & 189 & 189 & 189 & 0 & Kritis \\
\hline 18 & $\mathrm{CG}$ & 7 & 189 & 196 & 196 & 196 & 0 & Kritis \\
\hline 19 & $\mathrm{CH}$ & 7 & 196 & 203 & 203 & 203 & 0 & Kritis \\
\hline 20 & DA & 7 & 203 & 203 & 203 & 203 & 0 & Kritis \\
\hline 21 & EA & 7 & 203 & 203 & 203 & 203 & 0 & Kritis \\
\hline
\end{tabular}


Dari perhitungan total float, maka dapat ditentukan lintasan kritis, dimana lintasan kritis atau jalur kritis memiliki total float $=0$, didapatai penjelasan tersebut:

1. Yang memiliki total float $=0$ adalah kegiatan AA-BA-BB-BC-BE-BG-BH-BI-BJ-CA-CB-CC-CD-CECF-CH-CG-EA-DA, Maka jalur ini adalah kritis.

2. Kurun waktu penyelsaian pekerjaan dengan menggunakan metode Critical Path Methode adalah 203 Hari.

\section{SIMPULAN}

1. Pada Proyek pembangunan Mapolsek Danau Teluk Jambi bila menggunakan analisa network dalam perencanaan operasi pada pekerjaan proyek, maka akan terlihat dengan jelas susunan urutan kegiatan tersebut.

2. Berdasarkan pembahasan yang dilakukan pada bab IV, maka diperoleh jalur kritis sebagai berikut : kegiatan AA-BA-BB-BC-BE-BG-BH-BI-BJ-CA-CB-CC-CE-CD-CF-CH-CG-EA-DA

3. Kegiatan yang bersifat kritis berdampak pada waktu penyelsaian proyek secara keseluruhan jika durasi tiap kegiatan tersebut mengalami penundaan.

4. Dengan menggunakan metode Critical Path Methode dapat mempercepat waktu pelaksanaan proyek yang semula selesai dalam 238 hari dapat dipercepat menjadi 203 hari.

\section{DAFTAR PUSTAKA}

Erizal. (2007), Keselamatan Dan Kesehatan Kerja (K3), Insitut Pertanian Bogor Husen Abrar. (2008), Manajemen Kontruksi Proyek Perencanaan, Penjadwalan dan Pengendalian Proyek. Serpong. Andi.

Mosley W.H dan Bunggey J.H, Perencanaan Beton Bertulang Edisi Kedua. Erlangga. Jakarta

Widiantoro Ibnu. (2016), Laporan Praktik kerja Proyek Pembangunan GedungHotel Ibis STYLE Candilank. UKS. Semarang.

Yasin, H. Nazarkhan. (2003), Mengenal Kontrak Kontruksi di Indonesia. Buku Pertama Seri Konstruksi. Jakarta, PT. Gramedia Pustaka Utama.

Wulfram I. 2005. Manajemen Proyek Konstruksi. Yogyakarta: Andi Offset. 